\title{
Efficiency Analysis of a High-Specific Impulse Hall Thruster
}

\author{
Richard R. Hofer ${ }^{*}$ \\ QSS Group, Inc., Cleveland, OH, 44135, USA \\ Alec D. Gallimore ${ }^{\dagger}$ \\ University of Michigan, Ann Arbor, MI, 48109, USA
}

\begin{abstract}
Performance and plasma measurements of the high-specific impulse NASA-173Mv2 Hall thruster were analyzed using a phenomenological performance model that accounts for a partially-ionized plasma containing multiply-charged ions. Between discharge voltages of 300-900 V, the results showed that although the net decrease of efficiency due to multiplycharged ions was only $1.5-3.0 \%$, the effects of multiply-charged ions on the ion and electron currents could not be neglected. Between 300-900 V, the increase of the discharge current was attributed to the increasing fraction of multiply-charged ions, while the maximum deviation of the electron current from its average value was only $+5 /-14 \%$. These findings revealed how efficient operation at high-specific impulse was enabled through the regulation of the electron current with the applied magnetic field. Between 300-900 $\mathrm{V}$, the voltage utilization ranged from $89-97 \%$, the mass utilization from $86-90 \%$, and the current utilization from $77-81 \%$. Therefore, the anode efficiency was largely determined by the current utilization. The electron Hall parameter was nearly constant with voltage, decreasing from an average of 210 at $300 \mathrm{~V}$ to an average of 160 between 400-900 V. These results confirmed our claim that efficient operation can be achieved only over a limited range of Hall parameters.
\end{abstract}

\section{Nomenclature}

$\begin{array}{lll}A & = & \text { cross-sectional area of the annular discharge chamber } \\ B_{o} & = & \text { magnetic field normalization constant } \\ B_{r} & = & \text { radial component of the magnetic field } \\ B_{r, m a x} & = & \text { maximum radial magnetic field on the channel centerline } \\ E_{z} & = & \text { axial component of the electric field } \\ e & = & \text { electron charge } \\ I_{b} & = & \text { ion beam current, } \Sigma I_{i} \\ I_{d} & = & \text { discharge current } \\ I_{e} & = & \text { axial electron current } \\ I_{i} & = & \text { current of the } \mathrm{i}^{\text {th }} \text { ion species } \\ i & = & \text { ion charge-stage index }(1,2,3, \text { etc. }) \\ j_{e z} & = & \text { axial electron current density } \\ j_{e \theta} & = & \text { azimuthal electron current density } \\ \dot{m}_{a} & = & \text { anode mass flow rate } \\ \dot{m}_{b} & = & \text { ion beam mass flow rate, } \Sigma \dot{m}_{i} \\ \dot{m}_{c} & =\quad \text { cathode mass flow rate } \\ \dot{m}_{i} & =\quad \text { mass flow rate of the } \mathrm{i}^{\text {th }} \text { ion species }\end{array}$

\footnotetext{
* Research Scientist, richard.hofer@grc.nasa.gov, NASA Glenn Research Center, On-Board Propulsion Branch, 21000 Brookpark Rd., MS 301-3, AIAA Member.

${ }^{\dagger}$ Professor, Department of Aerospace Engineering, Plasmadynamics and Electric Propulsion Laboratory, Associate Fellow AIAA.
} 


\begin{tabular}{|c|c|c|}
\hline$\dot{m}_{t}$ & $=$ & total mass flow rate, $\dot{m}_{a}+\dot{m}_{c}$ \\
\hline$m_{x e}$ & $=$ & mass of a xenon atom \\
\hline$N$ & $=$ & total number of ion species \\
\hline$n_{b}$ & $=$ & ion beam number density, $\Sigma n_{i}$ \\
\hline$n_{e}$ & $=$ & electron number density \\
\hline$n_{i}$ & $=$ & number density of the $i^{\text {th }}$ ion species \\
\hline$P_{d}$ & $=$ & discharge power, $V_{d} I_{d}$ \\
\hline$P_{j e t}$ & $=$ & jet (or beam) power, $T^{2} / 2 \dot{m}_{t}$ \\
\hline$P_{\text {mag }}$ & $=$ & electromagnet coil power \\
\hline$P_{t}$ & $=$ & total input power, $P_{d}+P_{\text {mag }}$ \\
\hline$T$ & $=$ & thrust \\
\hline$V_{a}$ & $=$ & average acceleration voltage, $V_{d}-V_{l}$ \\
\hline$V_{d}$ & $=$ & discharge voltage \\
\hline$V_{l}$ & $=$ & ion loss voltage \\
\hline$V_{m p}$ & $=$ & most-probable ion voltage, $\approx V_{a}$ \\
\hline$V_{p}$ & $=$ & plasma potential \\
\hline$V_{r p a}$ & $=$ & uncorrected ion voltage \\
\hline$V_{\text {true }}$ & $=$ & corrected ion voltage \\
\hline$v_{E x B}$ & $=$ & ExB drift velocity \\
\hline$Z_{i}$ & $=$ & charge-state of the $\mathrm{i}^{\text {th }}$ ion species $(1,2,3$, etc. $)$ \\
\hline$\varepsilon$ & $=$ & electron current fraction, $I_{e} / I_{d}$ \\
\hline$\eta_{a}$ & $=$ & anode efficiency \\
\hline$\eta_{b}$ & $=$ & current utilization efficiency \\
\hline$\eta_{c}$ & $=$ & cathode efficiency, $\dot{m}_{a} / \dot{m}_{t}$ \\
\hline$\eta_{\text {mag }}$ & $=$ & electromagnet coil efficiency, $P_{d} / P_{t}$ \\
\hline$\eta_{m}$ & $=$ & mass utilization efficiency \\
\hline$\eta_{q}$ & $=$ & charge utilization efficiency \\
\hline$\eta_{v}$ & $=$ & voltage utilization efficiency \\
\hline$\eta_{t}$ & $=$ & total efficiency \\
\hline$\xi$ & $=$ & exchange ratio, $m_{x e} I_{d} / \dot{m}_{a} e$ \\
\hline$\zeta_{i}$ & $=$ & fraction of the $\mathrm{i}^{\text {th }}$ ion species, $n_{i} / n_{b}$ \\
\hline$\Omega_{\mathrm{e}}$ & $=$ & electron Hall parameter \\
\hline$\Omega_{\mathrm{i}}$ & $=$ & current fraction of the $\mathrm{i}^{\text {th }}$ ion species, $I_{i} / I_{b}$ \\
\hline
\end{tabular}

\section{Introduction}

WESTERN interest in Russian Hall thruster technology emerged in the 1990's partly because the $1600 \mathrm{~s}$ specific impulse characteristic of flight hardware fell between arcjets (less than $1000 \mathrm{~s}$ ) and gridded ion thrusters (greater than 3000 s) [1, 2]. After Russian Hall thrusters met western flight qualification standards in the mid-1990's, interest in expanding the specific impulse range developed, mostly towards $3000 \mathrm{~s}$, so that the Hall thruster could more fully bridge the 1000-3000 s specific impulse gap. These activities were motivated by studies indicating the substantial mission benefits for Earth orbiting [2-7] and interplanetary [7-12] spacecraft if Hall thrusters could operate efficiently at 2000-3000 s specific impulse.

Beginning in the late 1990's, NASA Glenn Research Center (GRC) sponsored a research program to investigate the feasibility of operating modern, xenon Hall thrusters at high-specific impulse. While the initial studies of commercially-developed Hall thrusters demonstrated greater than $4000 \mathrm{~s}$ specific impulse, maximum thruster efficiency occurred at less than $3000 \mathrm{~s} \mathrm{[13-15].} \mathrm{Follow-on} \mathrm{efforts} \mathrm{by} \mathrm{the} \mathrm{University} \mathrm{of} \mathrm{Michigan} \mathrm{and} \mathrm{GRC} \mathrm{focused}$ on the development and characterization of xenon Hall thrusters capable of both high-specific impulse and highefficiency operation [16-22]. The research resulted in the NASA-173M series of laboratory-model Hall thrusters. 
The thrusters were designed based on the hypothesis that the efficiency maximum observed with the commerciallydeveloped thrusters was actually a consequence of modern magnetic field designs that have been optimized for 1600 $\mathrm{s}$ specific impulse. The NASA-173M Hall thrusters were therefore an attempt to improve efficiency through the implementation of a magnetic field topography intended for high-specific impulse. The basis of the magnetic field design was a topography shaped as a plasma lens.

The role of the magnetic field in achieving efficient operation can be shown by considering the relationship between the electron Hall parameter, the axial electron current, and the magnetic field. First, as a basic operating principle of Hall thrusters the electron Hall parameter satisfies

$$
\Omega_{e}=\frac{j_{e \theta}}{j_{e z}}>>1 .
$$

(The Hall parameter characterizes the number of azimuthal orbits that a particle executes before being perturbed by particle collisions, collisions with the walls, or plasma fluctuations.) The high value of the Hall parameter, being much greater than unity but not infinite, implies that electrons undergo a sufficient number of ionizing collisions on their way to the anode to sustain the plasma discharge while still maintaining a bulk azimuthal current that is several times larger than the axial current. It is therefore reasonable to expect that efficient Hall thruster operation can only be achieved over a limited range of Hall parameters.

The relationship between the Hall parameter and thruster efficiency can be shown by considering the current utilization efficiency. The current utilization efficiency, which largely determines the anode efficiency, is given by

$$
\eta_{b}=\frac{I_{b}}{I_{d}}=\frac{1}{1+\left(I_{e} / I_{b}\right)} .
$$

For constant discharge current, Eqn. 2 shows how minimizing the electron current increases the current utilization by maximizing the ion yield. The electrons also largely determine the ionization efficiency (through their average temperature) and the acceleration efficiency (by establishing the self-consistent electric field). Clearly, an understanding of the electron dynamics is vital in the study of Hall thruster physics.

Unfortunately, the physics determining the axial electron current in a Hall thruster is a seemingly intractable problem that has plagued researchers for decades [23-31]. This is mainly due to the presence of anomalous diffusion mechanisms that increase the cross-field transport of electrons beyond that predicted by classical transport theory. The two leading candidates thought to be responsible for anomalous transport are collisions with the walls and turbulent plasma fluctuations. Determining which of these mechanisms is dominant has been the subject of considerable debate since the 1960's. A review of past experimental, numerical simulation, and theoretical research (see Ref. [16]), shows that it is likely that both mechanisms each play a role in different regions of the plasma and at different operating conditions. Fortunately, while a complete understanding of the electron dynamics has so far proven to be elusive, it is known that the electron dynamics can be influenced by controlling the shape and strength of the magnetic field. At least in this sense, it is fair to say then that the magnetic field is the most important aspect of Hall thruster design.

The significance of the magnetic field in achieving efficient operation at high-specific impulse has been verified with the NASA-173M Hall thrusters. Experiments with the NASA-173M version 1 (v1) validated the plasma lens design by showing how altering the magnetic field topography at high-specific impulse enhanced efficiency [18]. Later experiments with the NASA-173M version 2 (v2) demonstrated there was a minimum current density and optimum magnetic field topography at which efficiency monotonically increased with voltage [19]. Comparison of the thrusters has shown that efficiency can be optimized for specific impulse by varying the concavity of the plasma lens [16].

Design and experiment have established that Hall thrusters can operate efficiently at high-specific impulse. However, a need still exists to better understand the relationship between the thruster design and the plasma. This is necessary to further increase the performance, thermal margin, stability, and lifetime of future designs. To that end, a series of diagnostics were recently deployed with the NASA-173Mv2 in order to study the competing mechanisms affecting performance at high-specific impulse [16, 19-22].

In this paper, we consider the question of how the magnetic field enabled high-efficiency operation of the NASA-173Mv2. We begin by presenting the relevant details of a performance model derived in Ref. [16]. Select results from the diagnostic studies are then reviewed and analyzed in the context of the model. Our analysis 
demonstrates how efficient, high-specific impulse operation of the NASA-173Mv2 was enabled through the regulation of the electron current with the magnetic field. Further, we verify our claim that efficient operation can be achieved only over a limited range of electron Hall parameters by showing that the Hall parameter was nearly constant over a broad range of discharge voltages.

\section{Phenomenological Model of Hall Thruster Efficiency}

In this section, the essential details from a phenomenological Hall thruster performance model are presented [16]. The model expresses the performance of a Hall thruster as a function of the utilization efficiencies of current, mass, voltage, and charge by accounting for a partially-ionized plasma consisting of multiply-charged ions. When combined with experimental data, the model can be used to weigh the relative importance of various plasma properties affecting performance such as multiply-charged ions or the electron current. Although the model can be used to compute each of the performance parameters, only those portions of the model concerning efficiency are presented here.

Excluding the electrical efficiency of the systems that deliver power to a Hall thruster, the total thrust efficiency $\left(\eta_{t}\right)$ is the ratio of jet power in the exhaust to the total input power

$$
\eta_{t}=\frac{P_{j e t}}{P_{t}}=\frac{T^{2}}{2 \dot{m}_{a} P_{d}} \frac{P_{d}}{P_{t}} \frac{\dot{m}_{a}}{\dot{m}_{t}}=\eta_{a} \eta_{c} \eta_{m a g}
$$

The cathode efficiency $\left(\eta_{c}\right)$ and electromagnet efficiency $\left(\eta_{m a g}\right)$ account for the cathode flow rate and the power supplied to the electromagnet coils. Since these losses are not directly related to the production of useful thrust, the focus here is on the anode efficiency $\left(\eta_{a}\right)$.

The anode efficiency is determined by the efficiency of the ionization and acceleration processes. While these processes are interrelated and not easily separated analytically, one way to decompose the anode efficiency is by defining the following utilization efficiencies:

1. the fraction of multiply-charged ions in the plasma, that is, the charge utilization efficiency,

2. the conversion of voltage into axially directed ion velocity, that is, the voltage utilization efficiency,

3. the fraction of ion current contained in the discharge current, that is, the current utilization efficiency, and

4. the conversion of neutral mass flux into ion mass flux, that is, the mass utilization efficiency.

The anode efficiency is then the product of these four processes given by

$$
\eta_{a}=\frac{T^{2}}{2 \dot{m}_{a} P_{d}}=\eta_{q} \eta_{v} \eta_{b} \eta_{m}
$$

where the partial efficiencies are the charge utilization efficiency ${ }^{\ddagger}$

$$
\eta_{q}=\frac{\left(\sum^{\Omega_{i}} / \sqrt{Z_{i}}\right)^{2}}{\sum^{\Omega_{i}} / Z_{i}},
$$

the voltage utilization efficiency

$$
\eta_{v}=\frac{V_{a}}{V_{d}}=1-\frac{V_{l}}{V_{d}}
$$

\footnotetext{
* Throughout this paper, summations are for each ion species $i$ from 1 to $N$, where $N$ is the total number of ion species.
} 
the current utilization efficiency

$$
\eta_{b}=\frac{I_{b}}{I_{d}}=1-\varepsilon
$$

and the mass utilization efficiency

$$
\eta_{m}=\frac{\dot{m}_{b}}{\dot{m}_{a}}=\xi \eta_{b} \sum \frac{\Omega_{i}}{Z_{i}}
$$

The current, mass, and charge utilization efficiencies are interrelated due to their dependence on the ion current and the ion current fractions. Thus, the anode efficiency can also be expressed as

$$
\eta_{a}=\eta_{q} \eta_{v} \eta_{b} \eta_{m}=\overbrace{\left(1-\frac{V_{l}}{V_{d}}\right)}^{\eta_{v}} \underbrace{(1-\varepsilon)^{2} \xi\left(\sum \frac{\Omega_{i}}{\sqrt{Z_{i}}}\right)^{2}}_{\eta_{b} \eta_{m} \eta_{q}} .
$$

The electron current fraction $(\varepsilon)$ can be calculated using Eqn. 7 if the anode efficiency, ion current fractions, and ion loss voltage are known. Eqns. 3-6 can then be used to compute each of the utilization efficiencies. In this paper, the anode efficiency was measured with a thrust stand, the ion current fractions were measured with an ExB probe, and the ion loss voltage was measured with a retarding potential analyzer.

\section{Experimental Apparatus}

\section{A. NASA-173Mv2 Hall Thruster}

The laboratory-model NASA-173Mv2 is a single-stage, magnetic layer Hall thruster sized for a nominal discharge power of $5 \mathrm{~kW}$ (Figure 1; see Ref. [16] for a detailed description). The discharge chamber has an outer

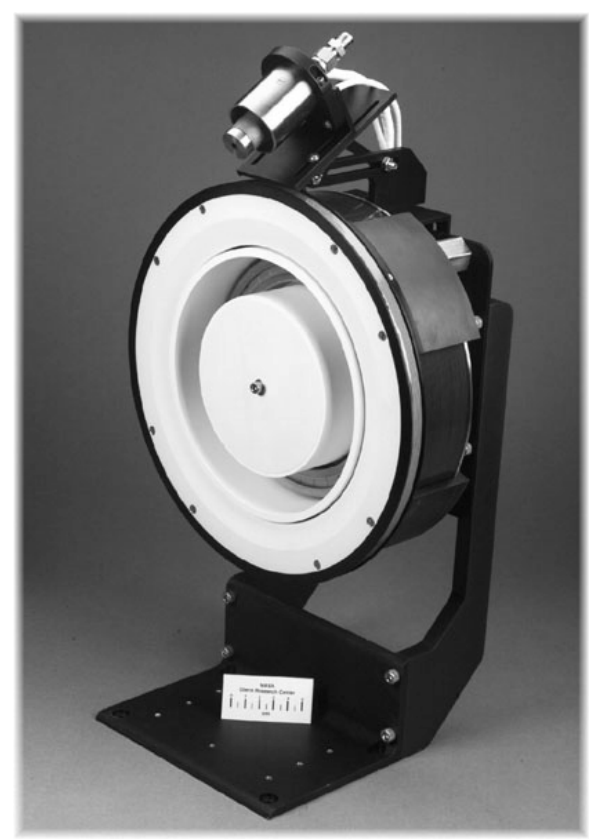

Figure 1. Photograph of the highspecific impulse NASA-173Mv2 Hall thruster. diameter of $173 \mathrm{~mm}$ and is made from boron nitride. The magnetic circuit is similar to the generic Hall thruster schematic shown in Figure 2. A fixed structure of iron poles pieces, an inner coil (IC) and an outer coil (OC) form the primary magnetic circuit. Fine control of the magnetic field is provided with an internal trim coil (ITC) and an external trim coil (ETC). The internal trim coil primarily affects the radial magnetic field in the discharge chamber, while the external trim coil affects the magnetic field downstream of the exit plane and near the cathode [16].

The thruster was powered with commercially available power supplies. The laboratory-model hollow cathode was a GRC design capable of emission currents up to 20 A. High-purity xenon was supplied with commercially available mass flow controllers that were calibrated before each experiment using a constant-volume method. Based on the calibrations from several experiments, the uncertainty was on average $\pm 0.8 \%$ for the anode flow rate and $\pm 1.2 \%$ for the cathode flow rate. Thruster telemetry was acquired using a 22-bit datalogger, which was calibrated using digital multimeters with uncertainties of $\pm 0.05 \%$ for voltage and $\pm 0.2 \%$ for current.

\section{B. Vacuum Facility 12}

All experiments were conducted in vacuum facility 12 (VF12) at GRC, which is described in detail in Ref. [16]. VF12 is a cryogenicallypumped, cylindrical, stainless steel vacuum chamber that is three meters 


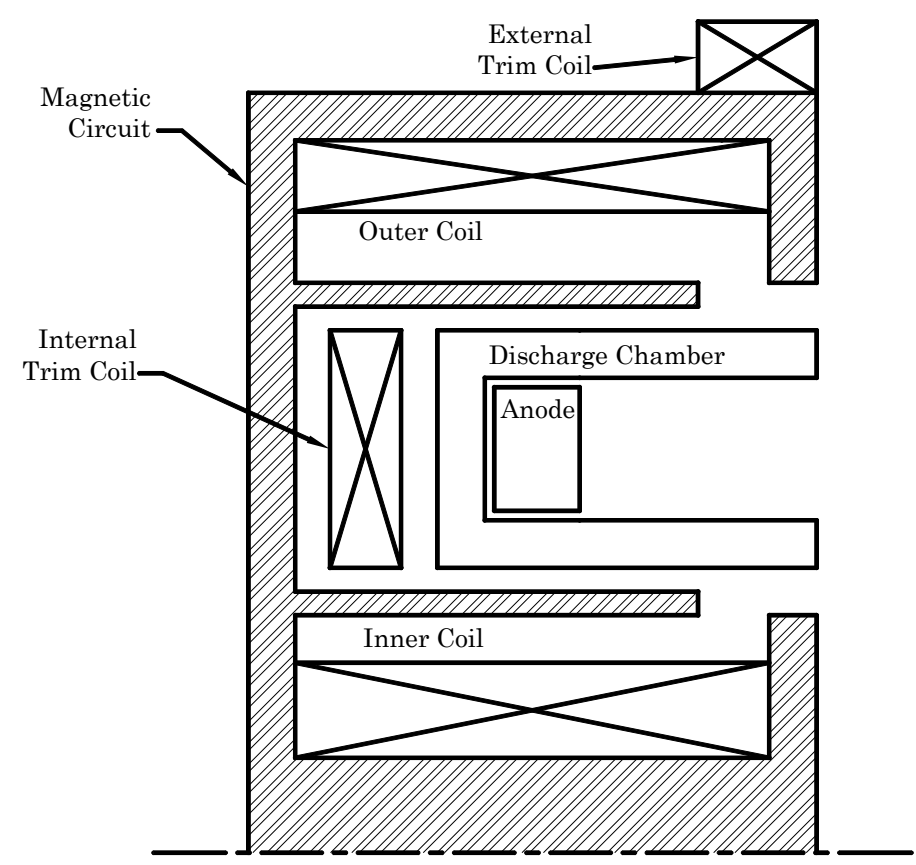

Figure 2. Generic Hall thruster schematic. (not to scale)

in diameter and 9.6 meters in length. The NASA-173Mv2 was always mounted on a thrust stand, with the thruster centerline near the chamber's vertical centerline, and fired $8.9 \mathrm{~m}$ down the length of the tank toward the cryopanels, which are located along the back half of VF12. When the ExB probe or RPA were used, they were located two meters downstream of the thruster exit plane on thruster centerline, within an accuracy of $\pm 0.5 \mathrm{~cm}$ in both the axial and radial directions (only one probe was in VF12 at a time during testing). A nitrogen calibrated hot-cathode ionization gauge recorded the background pressure. The indicated pressure measurements were corrected for xenon using the base pressure on air $\left(1.0 \times 10^{-7}\right.$ Torr $)$ and a correction factor of 2.87 for xenon. For a total xenon flow rate of $11 \mathrm{mg} / \mathrm{s}$, the corrected pressure was $4.6 \times 10^{-6}$ Torr.

\section{Thrust Stand}

Thrust measurements were taken using a null-mode, inverted-pendulum thrust stand designed at GRC and used previously in VF12 with a $10 \mathrm{~kW}$ Hall thruster [32]. The thrust stand was described in detail in Ref. [16, 19]. Measurement uncertainty was predominantly due to thermal drift and was estimated to be $\pm 0.5 \mathrm{mN}$. Repeatability was quantified by periodically returning to select operating points and was influenced more by the thruster (e.g., by returning to the same discharge current) than the thrust stand. For a given operating point, the repeatability of thrust measurements averaged $\pm 1 \%$ of the reported values.

\section{ExB Probe}

An ExB probe, or Wien filter, is a band-pass ion filter that selects ions according to their velocities through the application of crossed electric and magnetic fields [33-38]. Most probes establish a constant magnetic field with permanent magnets while the electric field is established between two parallel plates. Sweeping the plate voltage while monitoring the ion current that passes through the probe yields a current-voltage characteristic that is related to the ion velocity distribution function. Because the velocity of multiply-charged ions in Hall thrusters is proportional to the square root of their charge-state, an ExB probe can be used to discriminate between ion species. Analysis of the ion current peaks from the probe characteristic can then be used to compute the ion species fractions.

The ExB probe was based on previous designs used to study ion and Hall thrusters [36-38] and was described in detail in Ref. $[16,21]$. The acceptance angle of the probe was $0.7^{\circ}$. Probe resolution was conservatively estimated as $7 \%$ of the ion energy [36]. The entrance and exit collimators were aligned perpendicular to the thruster exit plane within an accuracy of $\pm 0.5^{\circ}$. After considering the known sources of error (see Ref. [16]), the absolute measurement uncertainty of the species fractions was estimated to be $\pm 0.04, \pm 0.02$, and \pm 0.01 for $\mathrm{Xe}^{+}, \mathrm{Xe}^{2+}$, and $\mathrm{Xe}^{3+}$, respectively. At $300 \mathrm{~V}$, this equated to a percentage uncertainty of $\pm 4 \%, \pm 50 \%$, and $\pm 100 \%$ for the species fractions of $\mathrm{Xe}^{+}, \mathrm{Xe}^{2+}$, and $\mathrm{Xe}^{3+}$, respectively.

\section{E. Retarding Potential Analyzer}

A retarding potential analyzer (RPA) selectively filters ions by applying a retarding potential across an inlet grid [39-41]. The probe acts as a high-pass filter by allowing only ions with voltages (i.e., energy-to-charge ratios) greater than the grid voltage to pass and reach a collection electrode. The derivative of the resulting current-voltage characteristic is then proportional to the ion voltage distribution function [39].

The RPA, which was a three-grid design described in detail in Ref. [16, 22], was provided by the Air Force Research Laboratory, Edwards Air Force Base, CA. Measurements of the ion voltage distribution were taken with respect to facility ground. Plasma potential $\left(V_{p}\right)$ measurements taken with a cylindrical Langmuir probe (not shown, see Ref. [16]) were used to correct the RPA data so that the true ion voltage distribution could be computed ( $V_{\text {true }}=$ 
$\left.V_{r p a}-V_{p}\right)$. The most-probable ion voltage $\left(V_{m p}\right)$ and the ion loss voltage $\left(V_{l}\right)$ were then found from the true ion voltage distribution. The most-probable ion voltage was defined as the voltage where the ion current was greatest. The ion loss voltage was then computed as the difference between the discharge voltage and the most-probable ion voltage $\left(V_{l}=V_{d}-V_{m p}\right)$. The acceptance angle of the probe was $45^{\circ}$. The face of the probe inlet was aligned parallel to the thruster exit plane within an accuracy of $\pm 0.5^{\circ}$. After considering the known sources of error (see Ref. [16]), the uncertainty of the most-probable voltage was estimated as $\pm 10 \mathrm{~V}$.

\section{F. Hall Probe}

A commercially available, three-axis Hall probe was used to measure the magnetic field of the NASA-173Mv2 at atmospheric conditions (no plasma). The Hall probe was described in detail in Ref. [16]. For the data presented here, the Hall probe was placed on the channel centerline at the axial location of the maximum radial magnetic field, which is near the discharge chamber exit plane. Before collecting data, the Hall probe was zeroed using a zeroGauss chamber with the thruster coils off and the probe located $300 \mathrm{~mm}$ from the thruster. As with all coaxial Hall thrusters, the NASA-173Mv2 magnetic circuit was designed so that the azimuthal magnetic field in the discharge chamber was negligible compared to the radial and axial components. This provided a convenient means to align the Hall probe before collecting data by orienting the probe such that the indicated azimuthal magnetic field was minimized, which insured that the full magnitude of the radial magnetic field was being measured. Measurement uncertainty, which was primarily due to positional and alignment errors, was estimated as $\pm 10 \%$.

\section{Results}

Performance and probe measurements of the NASA-173Mv2 in VF12 were conducted at mass flow rates of 10 $\mathrm{mg} / \mathrm{s}$ through the anode and $1.0 \mathrm{mg} / \mathrm{s}$ through the cathode. These flow rates were chosen because they have proven to be an acceptable balance between performance, thermal margin, and stability up to discharge voltages of $1000 \mathrm{~V}[16]$.

The performance evaluation established the coil currents that maximized thruster efficiency $[16,19]$. The general method for taking data was to set the voltage and flow rate and then investigate the effects of each coil on discharge current, plasma oscillations, and anode efficiency. The effects of changing the magnetic field topography were investigated by energizing the thruster coils in different combinations, which are labeled in the figures as:

1. IC, OC - only the inner and outer coils were energized,

2. ITC - the internal trim coil was energized in addition to the inner and outer coils,

3. ITC, ETC - both trim coils were energized in addition to the inner and outer coils, and

4. ETC - the external trim coil was energized in addition to the inner and outer coils.

The probe measurements $[16,21,22]$ used the coil currents found during the performance evaluation that maximized efficiency. The performance measurements usually did not include data with the external trim coil unless the internal trim coil was also energized. During the ExB probe and RPA experiments, the ETC coil combination was included at all discharge voltages so that the effects of the external trim coil could be investigated separate from the internal trim coil.

For all of the experiments, the thruster was operated for two to four hours after initial exposure to vacuum conditions to allow for outgassing of the discharge chamber walls. Upon subsequent thruster shutdowns and restarts or a change in the discharge voltage, the thruster was operated for at least 30-60 minutes before data were acquired. This procedure allowed enough time for the discharge current to reach a steady-state value.

\section{A. Anode Efficiency}

Measurements of the anode efficiency at $10 \mathrm{mg} / \mathrm{s}$ using the thrust stand were taken during a performance characterization that spanned $300-1000 \mathrm{~V}$ at 5 and $10 \mathrm{mg} / \mathrm{s}$ and $300-600 \mathrm{~V}$ at $15 \mathrm{mg} / \mathrm{s}[16,19]$. Figure 3 shows that the anode efficiency at $10 \mathrm{mg} / \mathrm{s}$ increased monotonically with voltage from $56.5 \%$ at $300 \mathrm{~V}$ to $68.5 \%$ at $1000 \mathrm{~V}$. Total efficiency (not shown) spanned the range of $51.1 \%$ at $300 \mathrm{~V}$ to $60.8 \%$ at $1000 \mathrm{~V}$. The trim coils provided a modest improvement to performance. When the trim coils were used, anode efficiency increased by an average of $1.2 \%$ (absolute) and the maximum increase was 3.0\% (absolute). The total efficiency improved with the trim coils by an average of $0.8 \%$ (absolute) and the maximum increase was $1.6 \%$ (absolute). It is worth noting that although the efficiency benefits due to the trim coils were modest, trim coils have also been shown to decrease plume divergence and the frequency and magnitude of plasma oscillations [16, 19]. 


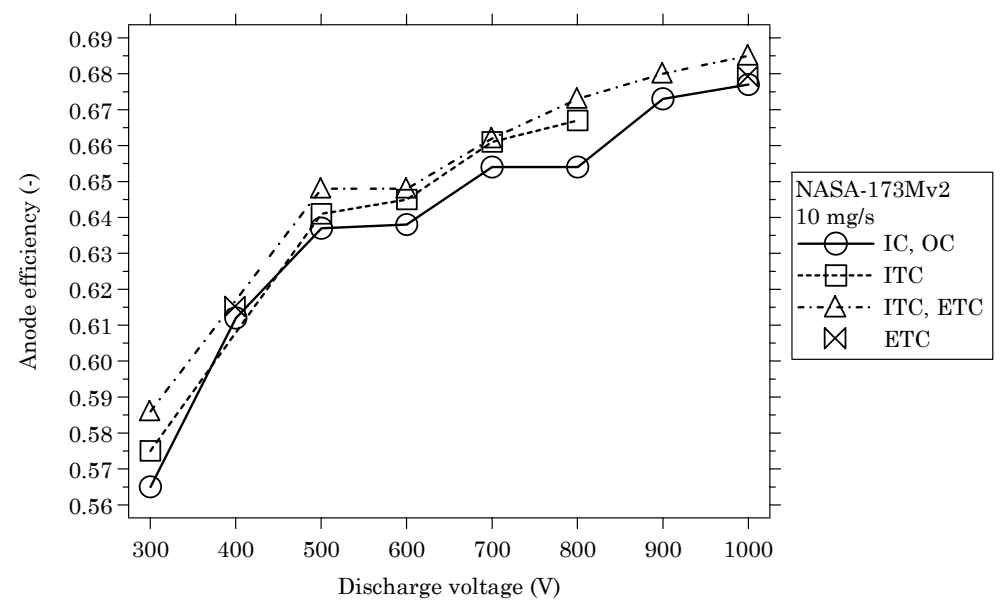

Figure 3. Anode efficiency versus discharge voltage of the NASA$173 \mathrm{Mv} 2$ at $10 \mathrm{mg} / \mathrm{s}$.

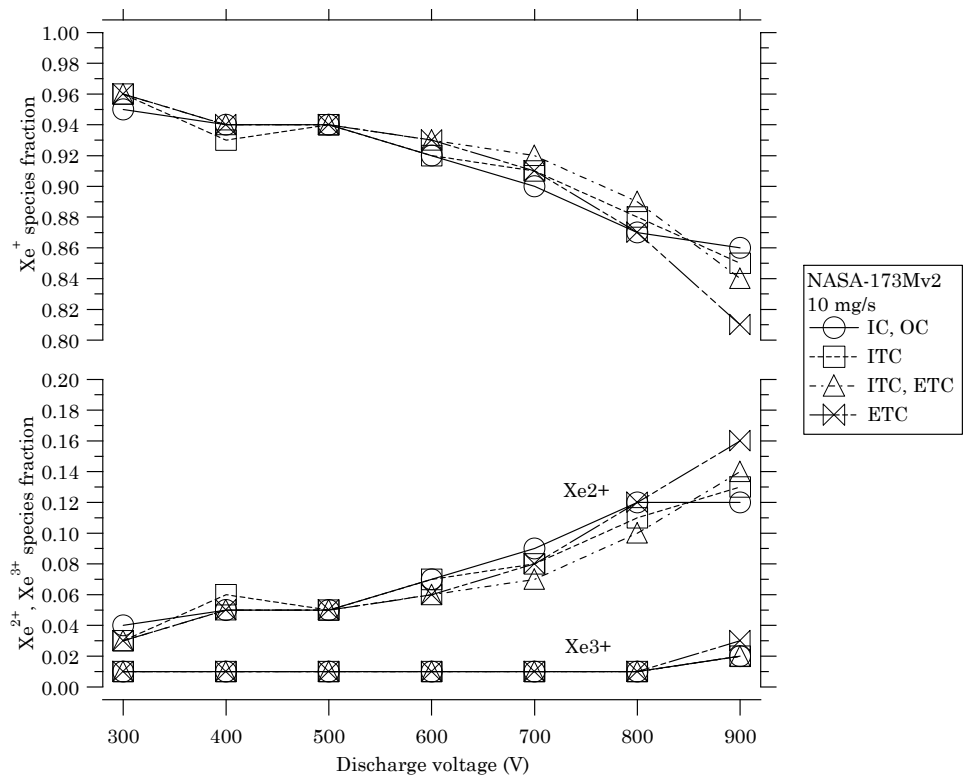

Figure 4. Ion species fractions versus discharge voltage of the NASA-173Mv2 at $10 \mathrm{mg} / \mathrm{s}$.

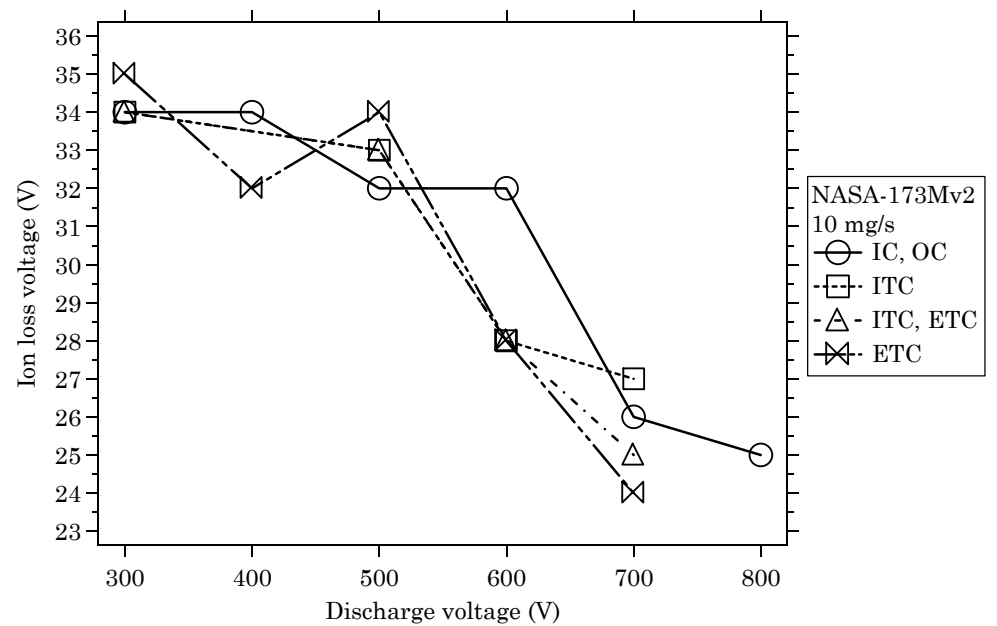

Figure 5. Ion loss voltage versus discharge voltage of the NASA$173 \mathrm{Mv} 2$ at $10 \mathrm{mg} / \mathrm{s}$.

\section{B. Ion Species Fractions}

Measurements with the ExB probe of the ion species fractions were taken at discharge voltages between 300-900 V $[16,21]$. The ion species fractions are shown in Figure 4 as a function of discharge voltage and magnetic field configuration. Although the fraction of multiply-charged ions increased with voltage, $\mathrm{Xe}^{+}$still dominated the plasma at all voltages. There was no systematic dependence of the species fractions with the magnetic field configuration. The $7 \%$ energy resolution of the ExB probe possibly contributed to this result by obscuring small changes of the ion species fractions. Between $300-900 \mathrm{~V}$, the species fraction of $\mathrm{Xe}^{+}$decreased from 0.96 to 0.81 . Over the same voltage range, the $\mathrm{Xe}^{2+}$ species fraction increased from 0.03 to 0.16 and the $\mathrm{Xe}^{3+}$ species fraction increased from 0.01 to 0.03 . At $300 \mathrm{~V}$, the fractions of $\mathrm{Xe}^{2+}$ and $\mathrm{Xe}^{3+}$ were lower, but still consistent with, Hall thruster studies [37, 42, 43] that have reported species fractions of 0.06-0.11 $\mathrm{Xe}^{2+}$ and $0.01 \mathrm{Xe}^{3+}$.

\section{Ion Loss Voltage}

Measurements with the RPA of the ion loss voltage were taken at discharge voltages between 300-800 V [16, 22]. A grid short with the RPA ended testing at $800 \mathrm{~V}$ after testing only with the inner and outer coils (IC,OC). The ion loss voltage is shown in Figure 5 as a function of discharge voltage and magnetic field configuration. There was no systematic dependence of the ion loss voltage with the magnetic field. Similar to the ExB probe, this may have been the result of the voltage resolution of the RPA. The ion loss voltage decreased with discharge voltage from $35 \mathrm{~V}$ at $300 \mathrm{~V}$ to $25 \mathrm{~V}$ at 800 $\mathrm{V}$. At $300 \mathrm{~V}$, the ion loss voltage was lower, but still consistent with Hall thruster studies [37, 43, 44] that have reported ion loss voltages between 45-50 V. 


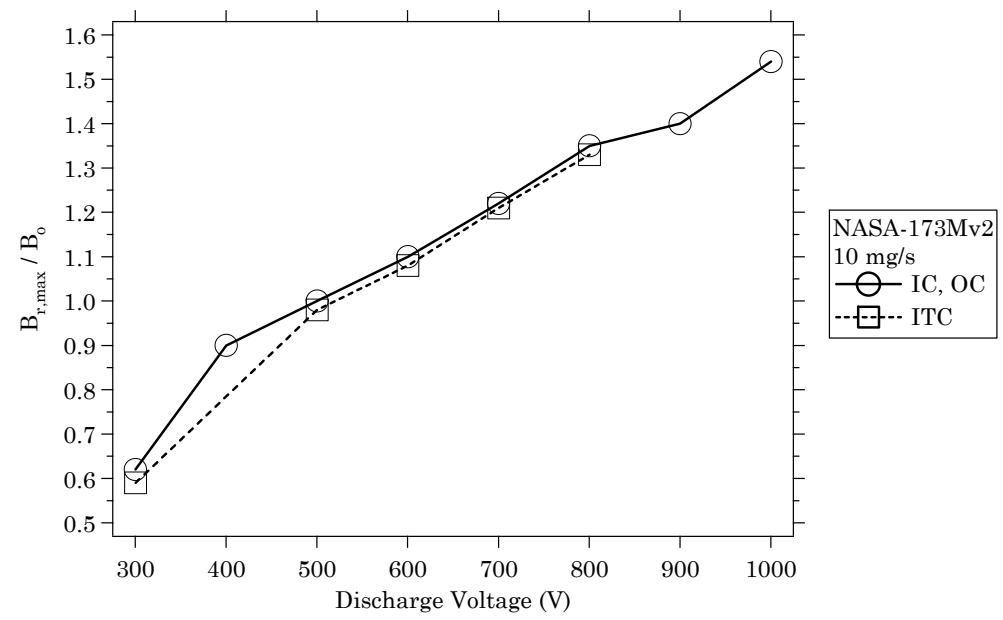

Figure 6. Radial magnetic field versus discharge voltage of the NASA-173Mv2 at $10 \mathrm{mg} / \mathrm{s}$. between $300-400 \mathrm{~V}$ (not shown, see Ref $[16,19]$ ). The magnetic field increased by a factor of 1.5 between $300-400$ $\mathrm{V}$ and by a factor of 1.7 between 400-1000 V. Between 300-1000 V, the magnetic field increased by a factor of 2.6.

\section{Discussion}

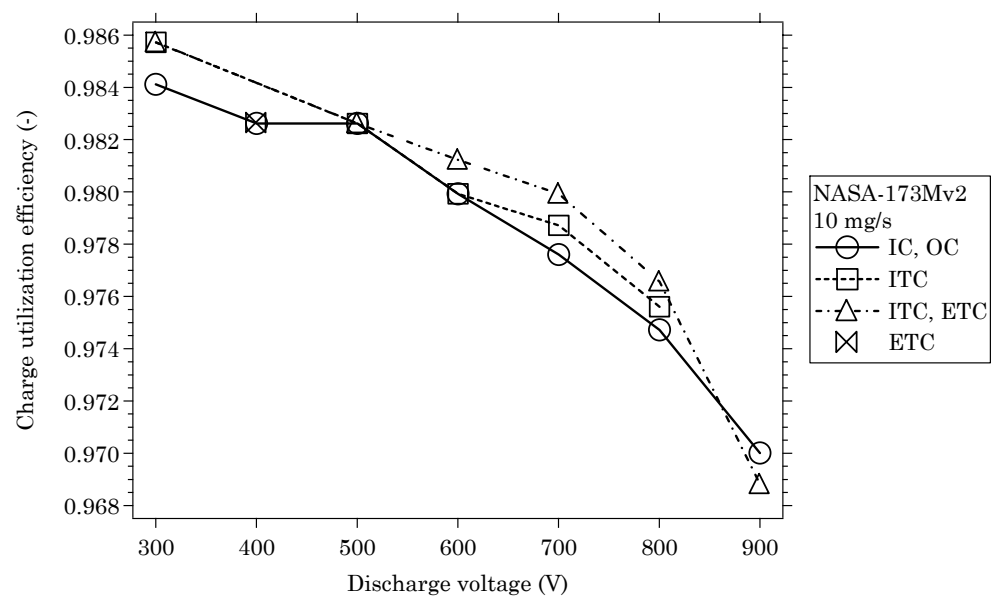

Figure 7. Charge utilization efficiency versus discharge voltage of the NASA-173Mv2 at $10 \mathrm{mg} / \mathrm{s}$. (Note compressed range on y-axis.)

\section{Magnetic Field Strength}

Measurements with the Hall probe of the maximum, radial magnetic field strength on the channel centerline were taken at the coil combinations corresponding to discharge voltages of 300-1000 V [16]. The magnetic field strength, normalized by an arbitrary constant $B_{o}$, is shown in Figure 6 for each of the coil combinations from the performance characterization. Operating points where the external trim coil was energized are not explicitly shown since the external trim coil has a negligible affect on the magnetic field in the discharge chamber. The magnetic field abruptly jumped between $300-400 \mathrm{~V}$ and then linearly increased between 400-1000 V. The increase in magnetic and discharge current oscillations also

\section{A. Charge utilization efficiency}

Figure 7 shows the charge utilization efficiency computed with Eqn. 3. The charge utilization averaged $98.5 \%$ at 300 $\mathrm{V}$ and then decreased at a nearly linear rate to an average of $97.6 \%$ at $800 \mathrm{~V}$. A (relatively) sharp decrease occurred between 800 and $900 \mathrm{~V}$, where the charge utilization dropped to an average of $97.0 \%$.

Although the charge utilization defined by Eqn. 3 does not include the effects of multiply-charged ions on the current or mass utilization, it can be shown that the charge utilization measures the net effect of multiply-charged ions on performance (see Ref. [16]). Thus, the net decrease of the anode efficiency due to the presence of multiply-charged ions averaged $1.5-3.0 \%$ between discharge voltages of $300-900 \mathrm{~V}$. This statement is not meant to imply that multiplycharged ions can be neglected in our analysis. In fact, multiply-charged ions significantly affect the ion current calculation and must be included (see section V.C).

\section{B. Voltage utilization efficiency}

Figure 8 shows the voltage utilization efficiency computed with Eqn. 4. The voltage utilization was computed only for the thruster operating points (i.e., coil combinations) that were studied during the performance characterization. The RPA data include all of the thruster operating points from the performance characterization between 300-700 V. At $800 \mathrm{~V}$, data with the RPA were acquired only with the inner and outer coils (IC,OC). No data were collected with the RPA at $900 \mathrm{~V}$. Since the voltage utilization showed a clear trend with discharge voltage, the ion loss voltage was conservatively extrapolated for the missing data points at 800 and $900 \mathrm{~V}$. The ion loss voltage was set to $25 \mathrm{~V}$ for the operating conditions at $800 \mathrm{~V}$ using the trim coils (the same as the measured

9

American Institute of Aeronautics and Astronautics 


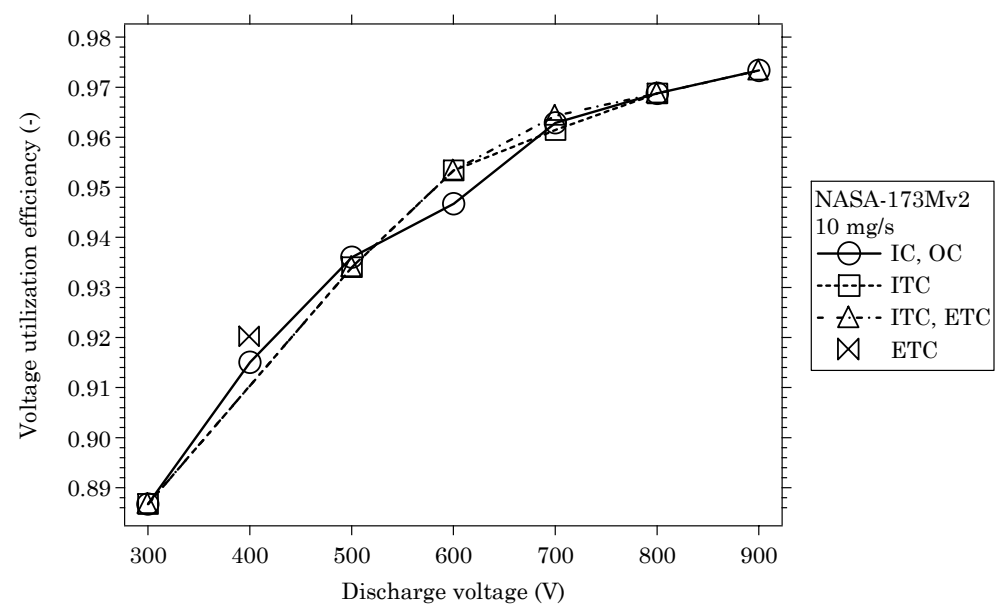

Figure 8. Voltage utilization efficiency versus discharge voltage of the NASA-173Mv2 at $10 \mathrm{mg} / \mathrm{s}$. (Note: Data at $800-900 \mathrm{~V}$ are extrapolated except for the $800 \mathrm{~V}$ [IC,OC] point.)

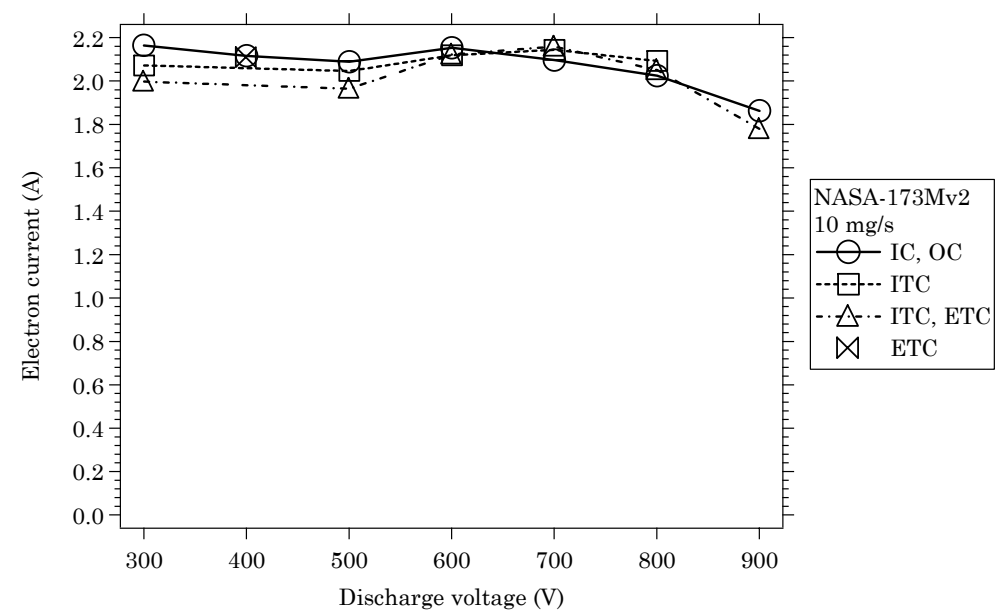

Figure 9. Electron current versus discharge voltage of the NASA$173 \mathrm{Mv} 2$ at $10 \mathrm{mg} / \mathrm{s}$.

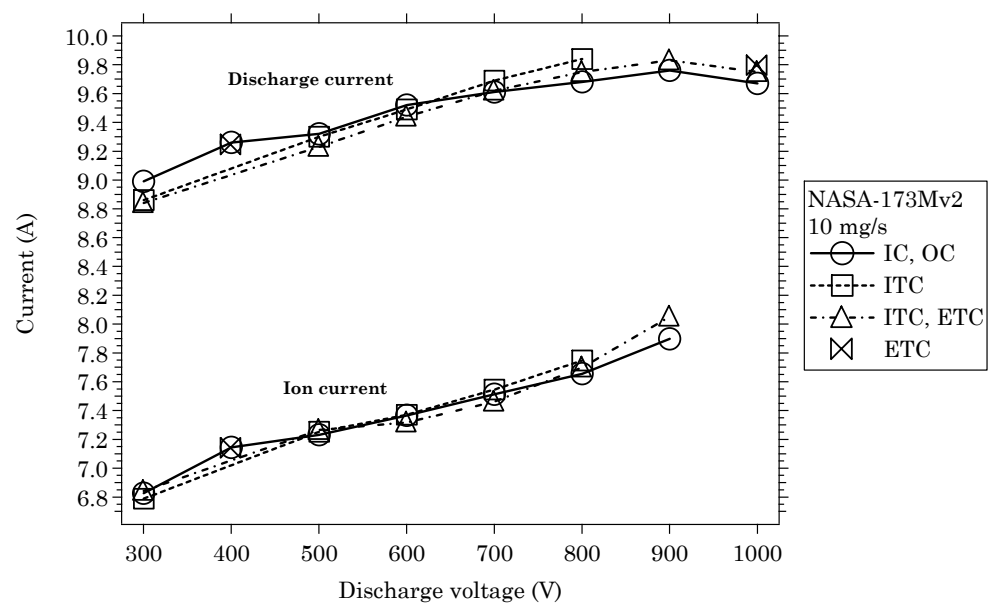

Figure 10. Ion current and discharge current versus discharge voltage of the NASA-173Mv2 at $10 \mathrm{mg} / \mathrm{s}$. value at $800 \mathrm{~V}[\mathrm{IC}, \mathrm{OC}])$. The ion loss voltage was set to $24 \mathrm{~V}$ for each data point at $900 \mathrm{~V}$, which was consistent with the observed decrease in ion loss voltage with increasing discharge voltage. Since Eqn. 7 depends on the ion loss voltage, note that the computations that follow in sections V.C through V.G are also based on these extrapolations.

Figure 8 shows that the voltage utilization averaged $88.7 \%$ at $300 \mathrm{~V}$ and increased to an average of $96.9 \%$ at $800 \mathrm{~V}$ (for the extrapolated data at $900 \mathrm{~V}$, the voltage utilization was 97.3\%). The increase of the voltage utilization was primarily the result of the discharge voltage increasing, since the decrease of the ion loss voltage was negligible in comparison.

\section{Electron and ion current}

Figure 9 shows the electron current computed with Eqn. 7. Since the discharge current was known, the ion current was also calculated and is shown along with the discharge current in Figure 10. The electron current was relatively constant between 300-700 $\mathrm{V}$ and then decreased between 700-900 V. The average value of the electron current between $300-900 \mathrm{~V}$ was $2.06 \mathrm{~A}$ with a maximum deviation of $+5 \% /-14 \%$ from the average. In contrast, the ion current steadily increased with discharge voltage from a minimum of $6.79 \mathrm{~A}$ at $300 \mathrm{~V}$ to a maximum of $8.05 \mathrm{~A}$ at $900 \mathrm{~V}$. The same relative increase in the ion current with voltage has been confirmed with unpublished results from a cathode-plane Faraday probe (not shown, the method employed was similar to Ref. [20]). The discharge current also increased with discharge voltage from a minimum of $8.84 \mathrm{~A}$ at $300 \mathrm{~V}$ to a maximum of $9.83 \mathrm{~A}$ at $900 \mathrm{~V}$. Thus, the increase in the discharge current was attributed to the increasing fraction of multiply-charged ions, rather than an increase of electron current. This demonstrates that the electron current in a high-specific impulse Hall thruster can be regulated if the magnetic field is of the appropriate shape and strength. These results also show that an increasing discharge current characteristic (Figure 10) should not be assumed to be the sole result of increasing 
electron current, especially if the thruster is operating efficiently. Finally, these results underscore the importance of including the effects of multiply-charged ions when analyzing the efficiency of high-specific impulse Hall thrusters.

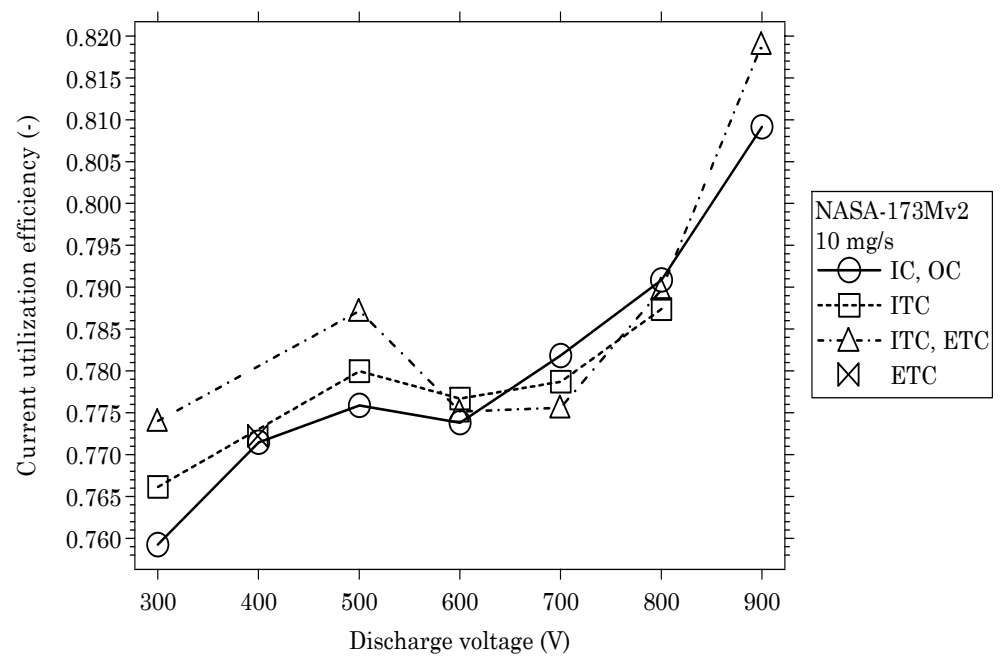

Figure 11. Current utilization efficiency versus discharge voltage of the NASA-173Mv2 at $10 \mathrm{mg} / \mathrm{s}$.

\section{Current utilization efficiency}

Figure 11 shows the current utilization efficiency computed with Eqn. 5 by using the ion and electron currents calculated in section V.C. The continuous increase of the ion current with voltage shown in Figure 10 was not reflected in the current utilization shown in Figure 11 since the current utilization depends on the ion and electron current. Instead, the current utilization initially increased between 300-500 V, was relatively constant between $500-700 \mathrm{~V}$, and then increased between 700-900 V. The rise in the current utilization beginning at $700 \mathrm{~V}$ was largely the result of the electron current decreasing (see Figure 9). Overall, since the electron current was nearly constant between $300-900 \mathrm{~V}$, the current utilization efficiency increased with voltage because of the increasing fraction of multiply-charged ions. The current utilization averaged $76.6 \%$ at $300 \mathrm{~V}$ and increased to an average of $81.4 \%$ at $900 \mathrm{~V}$. The computed current utilization efficiencies were consistent with the value of $77 \%$ previously measured with a cathode-plane Faraday probe with the NASA-173Mv2 operating at $500 \mathrm{~V}, 5 \mathrm{mg} / \mathrm{s}$ [20].

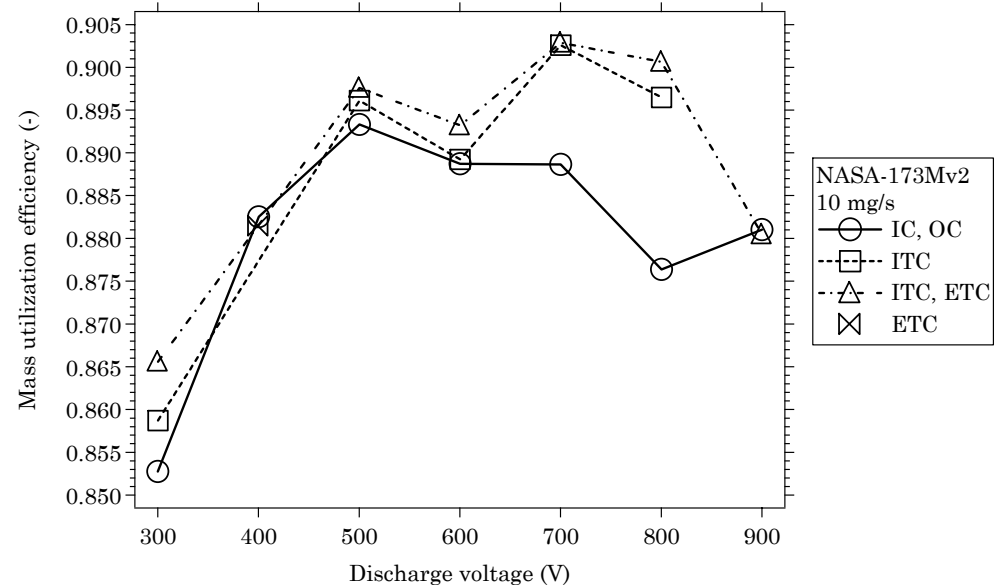

Figure 12. Mass utilization efficiency versus discharge voltage of the NASA-173Mv2 at $10 \mathrm{mg} / \mathrm{s}$.

\section{E. Mass utilization efficiency}

Figure 12 shows the mass utilization efficiency computed with Eqn. 6 by using the ion current that was calculated in section V.C. As shown in Figure 12, the mass utilization increased between 300$500 \mathrm{~V}$, was relatively constant between 500-700 V, and then showed evidence of a decrease between 700-900 V. The mass utilization averaged $85.9 \%$ at $300 \mathrm{~V}$ and $88.1 \%$ at $900 \mathrm{~V}$. The maximum mass utilization of $90.3 \%$ occurred at $700 \mathrm{~V}$.

The effects of multiply-charged ions are usually neglected in the literature, resulting in mass utilization efficiencies of $90-95 \%$ for discharge voltages of $300 \mathrm{~V}$ $[45,46]$. This is an adequate approximation so long as the discharge voltage is not much more than $300 \mathrm{~V}$. If multiply-charged ions had been neglected here, the mass utilization shown in Figure 12 would have been $3.4 \%$ (absolute) higher at $300 \mathrm{~V}$ and $9.3 \%$ (absolute) higher at $900 \mathrm{~V}$. (The current utilization shown in Figure 11 would have then been $3.4 \%$ (absolute) lower at $300 \mathrm{~V}$ and $9.3 \%$ (absolute) lower at $900 \mathrm{~V}$.) This demonstrates that the approximation of a singly-charged plasma begins to breakdown above $300 \mathrm{~V}$ as the fraction of multiply-charged ions increase with the discharge voltage, necessitating the inclusion of the effects of multiply-charged ions in our calculations. 


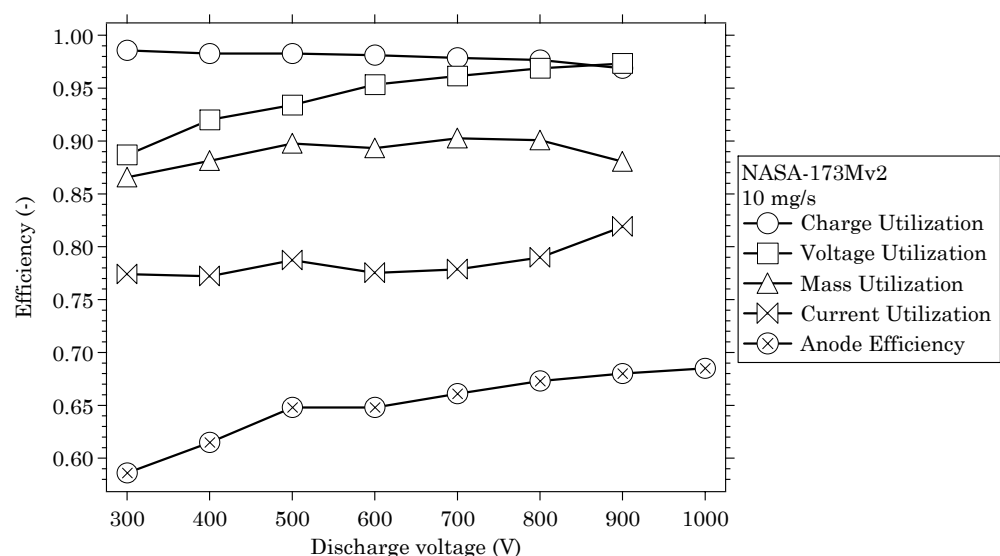

Figure 13. Optimized anode efficiency and the corresponding utilization efficiencies versus discharge voltage of the NASA$173 \mathrm{Mv} 2$ at $10 \mathrm{mg} / \mathrm{s}$. decrease above $700 \mathrm{~V}$ ), these results imply that the maximum anode efficiency of Hall thrusters has not yet been reached. Anode efficiencies can potentially still be increased, perhaps as high as $80 \%$, if the discharge voltage is increased beyond $1000 \mathrm{~V}$. At discharge voltages less than $1000 \mathrm{~V}$, since the electron current was relatively constant, further efficiency improvements require a means to minimize the production of multiply-charged ions while increasing the voltage and mass utilization. Since substantial increases in the charge or voltage utilization seem unlikely, increasing the anode efficiency below $1000 \mathrm{~V}$ will depend on a means to increase the mass utilization, such as the well known effects of high-current density or high-power operation $[45,46]$.

\section{G. Electron Hall Parameter}

The scaling of the axial electron current with voltage provides insight on the electron Hall parameter. The Hall parameter can be computed from the ratio of the azimuthal and axial electron current densities (see Eqn. 1). The azimuthal electron current density can be calculated from

$$
j_{e \theta}=n_{e} e v_{E x B}=n_{e} e \frac{E_{z}}{B_{r}} .
$$

The axial electron current density can be computed from the electron current and the annular cross-sectional area of the discharge chamber given by

$$
j_{e z}=\frac{I_{e}}{A}
$$

After applying the quasineutrality condition $\left(n_{e} \approx n_{b}\right)$ and substituting Eqns. 8 and 9, the Hall parameter from Eqn. 1 becomes

$$
\Omega_{e}=\frac{n_{b} e E_{z} A}{B_{r} I_{e}} .
$$

Besides the electron current and discharge chamber area, the Hall parameter was calculated from the available data as follows:

1. the axial electric field at $300 \mathrm{~V}$ was estimated from typical electric field strengths in modern Hall thrusters and then linearly varied with discharge voltage [16, 20, 47],

2. the radial magnetic field was taken from the Hall probe measurements shown in Figure 6, and

3. the beam density $\left(n_{b}\right)$ was computed from an expression derived in Ref. [16] as 


$$
I_{b}=\sum I_{i}=A e^{3 / 2} n_{b} \sqrt{\frac{2 V_{a}}{m_{x e}}} \sum \xi_{i} Z_{i}^{3 / 2} .
$$

Since Eqn. 10 is based on global thruster properties, the resulting Hall parameter should be interpreted as a bulk, or average value that is representative of the closed-drift region where the plasma density is high and the ions are being accelerated through the majority of the applied voltage. This is an important point to make since timeaveraged measurements of the Hall parameter from Ref. [48-50] have shown a strong spatial dependence throughout the discharge chamber. These studies have shown that the Hall parameter attains a maximum value of several hundred in the closed-drift region and then falls to the Bohm value (i.e., 16) near the anode and downstream of the exit plane.

Figure 14 shows that the Hall parameter computed with Eqn. 10 was an order of magnitude larger than the Bohm value. At $300 \mathrm{~V}$, the Hall parameter averaged 210. Between 300-400 V, the Hall parameter decreased by $25 \%$ and

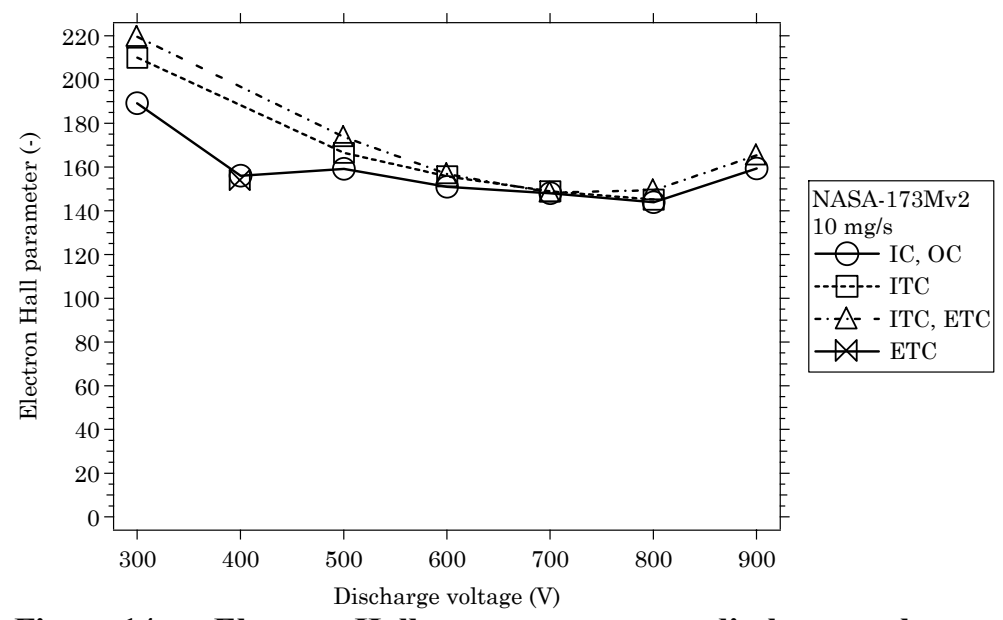

Figure 14. Electron Hall parameter versus discharge voltage of the NASA-173Mv2 at $10 \mathrm{mg} / \mathrm{s}$. then was nearly constant between 400-900 V. Between 400-900 V, the Hall parameter averaged 160 with a maximum deviation from the average of $+12 \% /-7 \%$. The computed Hall parameter was consistent with experimental investigations [48-50] that have shown that the Hall parameter attains a value of several hundred in the closed-drift region, and with numerical simulations [23, 27] that have found acceptable results when a fitting constant related to the Hall parameter was approximately 100 .

The decrease in the Hall parameter between 300-400 V likely coincided with the onset of space-charge saturation of the discharge chamber wall sheaths due to intense secondary electron emission $[25,26]$. Although this claim cannot be confirmed directly with the available data, there is ample evidence that the thruster is transitioning to a different operating mode beginning around $400 \mathrm{~V}$. For example, measurements of the plume divergence and discharge current oscillations between 300-400 V both show large increases (not shown, see Ref. [16, 19]) . Also, the required magnetic field (Figure 6) also sharply increases between $300-400 \mathrm{~V}$. The transition to this new regime most likely persists until about $600 \mathrm{~V}$, after which the discharge current oscillations suddenly decrease. It seems then that the magnetic field in the NASA-173Mv2 is effective at controlling oscillations and wall effects above $600 \mathrm{~V}$ so that the efficiency does not reach a maximum.

At least between 400-1000 V, maintaining a nearly constant Hall parameter over such a large voltage range implied that the balance of all the processes affecting the axial electron mobility was also approximately constant. This confirms our earlier claim that efficient thruster operation can only be achieved over a limited range of Hall parameters.

\section{Conclusion}

When combined with data from performance and plasma measurements, the results from a phenomenological Hall thruster performance model have provided new insights on the factors affecting efficiency during high-specific impulse operation. Between discharge voltages of 300-900 V, analysis has shown that although the net decrease of efficiency due to multiply-charged ions was only $1.5-3.0 \%$, the effects of multiply-charged ions on the ion and electron currents could not be neglected. The increase of the discharge current with discharge voltage was attributed to the increasing fraction of multiply-charged ions, while the electron current was found to be nearly constant. These findings revealed how efficient operation at high-specific impulse was enabled through the regulation of the electron current with the applied magnetic field. Additionally, the current utilization was always less than the other partial efficiencies composing the anode efficiency, which confirmed the expected result that the anode efficiency is largely determined by the current utilization. Finally, it was shown that the electron Hall parameter was nearly constant 
with voltage, which verified our claim that efficient operation can be achieved only over a limited range of Hall parameters.

The research on the NASA-173M Hall thrusters has established a solid foundation from which the development of high-specific impulse Hall thrusters may continue. While the design of such a thruster is currently in progress at NASA GRC [51], there are several other issues and potential directions that deserve further scrutiny. These topics are briefly discussed below.

Numerical simulations of high-specific impulse Hall thrusters. While our analysis has provided new insights not previously available, a more fundamental explanation of the factors affecting efficiency at high-specific impulse will probably require numerical modeling. Such efforts would likely be similar to those of Barral, et al. [26], and most certainly must include multiply-charged ions. The NASA-173Mv2 data is well-suited to validate the outputs from such models.

Lifetime evaluation of high-specific impulse Hall thrusters. This research has tacitly assumed that if thruster efficiency is maximized so too is thruster lifetime. While this may prove to be accurate, there are still questions concerning the rate at which lifetime decreases with voltage. Modeling by Garrigues, et al. [52] has begun to address some of these issues by demonstrating how erosion rates in $1600 \mathrm{~s}$ specific impulse thrusters decrease when a plasma lens is used (in lieu of less concave magnetic field lines). Efforts to predict the operational lifetime of NASA Hall thrusters are also currently be pursued [53].

Characterization of high-specific impulse Hall thrusters with krypton propellant. Besides offering higher specific impulse, krypton may prove to be a better propellant than xenon at high-specific impulse since the thruster lifetime should be higher. While ionizing krypton requires more energy than xenon (which decreases the mass utilization efficiency), this attribute also decreases the production of multiply-charged ions. The lower mass of krypton with respect to xenon also decreases the sputtering yield approximately by the square root of the mass ratio [54]. If Hall thruster efficiency on krypton can be improved to approach that of xenon, a krypton thruster could benefit several interplanetary missions due to the higher specific impulse and longer lifetime. Recent investigations of several NASA Hall thrusters operating on krypton have shown promise, where total efficiencies greater than $50 \%$ have been measured [51].

\section{Acknowledgments}

Program support for this research through Code R Energetics funding is gratefully acknowledged.

\section{References}

[1] Kaufman, H. R., "Technology of closed-drift thrusters," AIAA Journal, Vol. 23, No. 1, pp. 78-87, 1985.

[2] Oleson, S. R. and Sankovic, J. M., "Advanced Hall electric propulsion for future in-space transportation," NASA-TM-210676, NASA Glenn Research Center, Cleveland, OH, 2001.

[3] Gulczinksi, F. S. and Spores, R. A., "Analysis of Hall-effect thrusters and ion engines for orbit transfer missions," AIAA-96-2973, 32nd Joint Propulsion Conference, Lake Buena Vista, FL, July 1-3, 1996.

[4] Raitses, Y., Guelman, M., Ashkenazy, J., and Appelbaum, G., "Orbit transfer with a variable thrust Hall thruster under drag," Journal of Spacecraft and Rockets, Vol. 36, No. 6, pp. 875-881, 1998.

[5] Oleson, S. R., "Advanced electric propulsion for space solar power satellites," AIAA-99-2872, 35th Joint Propulsion Conference, Los Angeles, CA, June 20-24, 1999.

[6] Oleson, S. R., "Advanced electric propulsion for RLV launched geosynchronous spacecraft," IEPC-99-185, 26th International Electric Propulsion Conference, Kitakyushu, Japan, Oct. 17-21, 1999.

[7] Oleson, S. R., "Mission advantages of constant power, variable Isp electrostatic thrusters," AIAA-20003413, 36th Joint Propulsion Conference, Huntsville, AL, July 17-19, 2000.

[8] Dudzinski, L. A., Hack, K. J., Gefert, L. P., Kerslake, T. W., et al., "Design of a solar electric propulsion transfer vehicle for a non-nuclear human mars exploration architecture," IEPC-99-181, 26th International Electric Propulsion Conference, Kitakyushu, Japan, Oct. 17-21, 1999.

[9] Fiehler, D. and Oleson, S., "A comparison of electric propulsion systems for Mars exploration," AIAA2003-4574, 39th Joint Propulsion Conference, Huntsville, AL, July 20-23, 2003.

[10] Gefert, L. P., Hack, K. J., and Kerslake, T. W., "Options for the human exploration of mars using solar electric propulsion," AIP Conference Proceedings No. 458, Space Technology and Applications International Forum (STAIF), Albuquerque, NM, Jan. 31 - Feb. 4, 1999.

[11] Brophy, J. R. and Noca, M., "Electric propulsion for solar system exploration," Journal of Propulsion and Power, Vol. 14, No. 5, pp. 700-707, 1998. 
[12] Noca, M. and Brophy, J. R., "Over powering solar system exploration," AIAA-97-2914, 33rd Joint Propulsion Conference, Seattle, WA, July 6-9, 1997.

[13] Jacobson, D. T., Jankovsky, R. S., Rawlin, V. K., and Manzella, D. H., "High voltage TAL performance," AIAA-2001-3777, 37th Joint Propulsion Conference, Salt Lake City, UT, July 8-11, 2001.

[14] Manzella, D. H., Jacobson, D. T., and Jankovsky, R. S., "High Voltage SPT Performance," AIAA-20013774, 37th Joint Propulsion Conference, Salt Lake City, UT, July 8-11, 2001.

[15] Pote, B. and Tedrake, R., "Performance of a high specific impulse Hall thruster," IEPC-01-35, 27th International Electric Propulsion Conference, Pasadena, CA, Oct. 15-19, 2001.

[16] Hofer, R. R., "Development and characterization of high-efficiency, high-specific impulse xenon Hall thrusters," Ph.D. dissertation, Dept. of Aerospace Engineering, University of Michigan, Ann Arbor, MI, 2004.

[17] Hofer, R. R., Peterson, P. Y., Gallimore, A. D., and Jankovsky, R. S., "A high specific impulse two-stage Hall thruster with plasma lens focusing," IEPC-01-36, 27th International Electric Propulsion Conference, Pasadena, CA, October 15-19, 2001.

[18] Hofer, R. R. and Gallimore, A. D., "The role of magnetic field topography in improving the performance of high-voltage Hall thrusters," AIAA-2002-4111, 38th Joint Propulsion Conference, Indianapolis, IN, July 7$10,2002$.

[19] Hofer, R. R. and Jankovsky, R. S., "The influence of current density and magnetic field topography in optimizing the performance, divergence, and plasma oscillations of high specific impulse Hall thrusters," IEPC-2003-142, 28th International Electric Propulsion Conference, Toulouse, France, March 17-21, 2003.

[20] Hofer, R. R. and Gallimore, A. D., "Recent results from internal and very-near-field plasma diagnostics of a high specific impulse Hall thruster," IEPC-2003-037, 28th International Electric Propulsion Conference, Toulouse, France, March 17-21, 2003.

[21] Hofer, R. R. and Gallimore, A. D., "Ion species fractions in the far-field plume of a high-specific impulse Hall thruster," AIAA-2003-5001, 39th Joint Propulsion Conference, Huntsville, AL, July 20-23, 2003.

[22] Hofer, R. R., Haas, J. M., and Gallimore, A. D., "Ion voltage diagnostics in the far-field plume of a highspecific impulse Hall thruster," AIAA-2003-4556, 39th Joint Propulsion Conference, Huntsville, AL, July 20-23, 2003.

[23] Fife, J. M., "Hybrid-PIC modeling and electrostatic probe survey of Hall thrusters," Ph.D. Dissertation, Dept. of Aeronautics and Astronautics, Massachusetts Institute of Technology, Cambridge, MA, 1998.

[24] Morosov, A. I., Esipchuk, Y. V., Tilinin, G. N., Trofimov, A. V., et al., "Plasma accelerator with closed electron drift and extended acceleration zone," Soviet Physics Technical Physics, Vol. 17, No. 1, 1972.

[25] Gascon, N., Dudeck, M., and Barral, S., "Wall material effects in stationary plasma thrusters I: Parametric studies of an SPT-100," Physics of Plasmas, Vol. 10, No. 10, pp. 4123-4136, 2003.

[26] Barral, S., Makowski, K., Peradzynski, Z., Gascon, N., et al., "Wall material effects in stationary plasma thrusters II: Near-wall and in-wall conductivity," Physics of Plasmas, Vol. 10, No. 10, pp. 4137-4152, 2003.

[27] Ahedo, E., Gallardo, J. M., and Martinez-Sanchez, M., "Effects of the radial plasma-wall interaction on the Hall thruster discharge," Physics of Plasmas, Vol. 10, No. 8, pp. 3397-3409, 2003.

[28] Boeuf, J. P. and Garrigues, L., "Low frequency oscillations in a stationary plasma thruster," Journal of Applied Physics, Vol. 84, No. 7, 1998.

[29] Boeuf, J. P., Garrigues, L., and Pitchford, L. C., "Modeling of a magnetized plasma: the stationary plasma thruster," in Electron kinetics and applications of glow discharges, Kortshagen, U. and Tsendin, L., Eds., Plenum Press, 1998.

[30] Ivanov, A. A., Ivanov, A. A., and Bacal, M., "Effect of plasma-wall recombination on the conductivity in Hall thrusters," Plasma Physics and Controlled Fusion, Vol. 44, pp. 1463-1470, 2002.

[31] Janes, G. S. and Lowder, R. S., "Anomalous electron diffusion and ion acceleration in a low-density plasma," Physics of Fluids, Vol. 9, No. 6, 1966.

[32] Mason, L. S., Jankovsky, R. S., and Manzella, D. H., "1000 hours of testing on a 10 kilowatt Hall effect thruster," AIAA-2001-3773, 37th Joint Propulsion Conference, Salt Lake City, UT, July 8-11, 2001.

[33] Seliger, R. L., "ExB mass-separator design," Journal of Applied Physics, Vol. 43, No. 5, 1972.

[34] Vahrenkamp, R. P., "Measurement of double charged ions in the beam of a 30-cm mercury bombardment thruster," AIAA-73-1057, 10th International Electric Propulsion Conference, Lake Tahoe, NV, Oct. 31Nov. 2, 1973.

[35] Anderson, J. R. and Fitzgerald, D., "Fullerene propellant research for electric propulsion," AIAA-96-3211, 1996. 
[36] Kim, S. W., "Experimental investigations of plasma parameters and species-dependent ion energy distribution in the plasma exhaust plume of a Hall thruster," Ph.D. dissertation, Dept. of Aerospace Engineering, University of Michigan, Ann Arbor, MI, 1999.

[37] Kim, S.-W. and Gallimore, A. D., "Plume study of a 1.35-kW SPT-100 using an ExB probe," Journal of Spacecraft and Rockets, Vol. 39, No. 6, 2002.

[38] Williams, G. J., Domonkos, M. T., and Chavez, J. M., "Measurement of doubly charged ions in ion thruster plumes," IEPC-01-310, 27th International Electric Propulsion Conference, Pasadena, CA, Oct. 15-19, 2001.

[39] King, L. B., "Transport-property and mass spectral measurements in the plasma exhaust plume of a Hall effect space propulsion system," Ph.D. Dissertation, Dept. of Aerospace Engineering, University of Michigan, Ann Arbor, MI, 1998.

[40] Hutchinson, I. H., Principles of plasma diagnostics, 1st ed., Cambridge, Cambridge University Press, 1987.

[41] Beal, B. E. and Gallimore, A. D., "Energy analysis of a Hall thruster cluster," IEPC-2003-035, 28th International Electric Propulsion Conference, Toulouse, France, March 17-21, 2003.

[42] King, L. B. and Gallimore, A. D., "Mass spectral measurements in the plume of an SPT-100 Hall thruster," Journal of Propulsion and Power, Vol. 16, No. 6, pp. 1086-1092, 2000.

[43] Gulczinksi, F. S. and Gallimore, A. D., "Near-field ion energy and species measurements of a 5-kW Hall thruster," Journal of Propulsion and Power, Vol. 17, No. 2, pp. 418-427, 2001.

[44] King, L. B. and Gallimore, A. D., "Ion-energy diagnostics in the plasma exhaust plume of a Hall thruster," Journal of Propulsion and Power, Vol. 16, No. 5, 2000.

[45] Kim, V., "Main physical features and processes determining the performance of stationary plasma thrusters," Journal of Propulsion and Power, Vol. 14, No. 5, pp. 736-743, 1998.

[46] Zhurin, V. V., Kaufman, H. R., and Robinson, R. S., "Physics of closed drift thrusters," Plasma Sources Science and Technology, Vol. 8, No. 1, pp. R1-R20, 1999.

[47] Raitses, Y., Staack, D., Dorf, L., and Fisch, N. J., "Experimental study of acceleration region in a $2 \mathrm{~kW}$ Hall thruster," AIAA-2003-5153, 39th Joint Propulsion Conference, Huntsville, AL, July 20-23, 2003.

[48] Haas, J. M., "Low-perturbation interrogation of the internal and near-field plasma structure of a Hall thruster using a high-speed probe positioning system," Ph.D. Dissertation, Dept. of Aerospace Engineering, University of Michigan, Ann Arbor, MI, 2001.

[49] Choueiri, E. Y., "Plasma oscillations in Hall thrusters," Physics of Plasmas, Vol. 8, No. 4, pp. 1411-1426, 2001.

[50] Bishaev, A. M. and Kim, V., "Local plasma properties in a Hall-current accelerator with an extended acceleration zone," Soviet Physics Technical Physics, Vol. 23, No. 9, 1978.

[51] Jacobson, D. T., Manzella, D. H., Hofer, R. R., and Peterson, P. Y., "NASA's 2004 Hall Thruster Program," AIAA-2004-3600, 40th Joint Propulsion Conference, Ft. Lauderdale, FL, July 11-14, 2004.

[52] Garrigues, L., Hagelaar, G. J. M., Bareilles, J., Boniface, C., et al., "Model study of the influence of the magnetic field configuration on the performance and lifetime of a Hall thruster," Physics of Plasmas, Vol. 10, No. 12, pp. 4886-4892, 2003.

[53] Manzella, D. H., Yim, J., and Boyd, I. D., "Predicting Hall Thruster Operational Lifetime," AIAA-20043953, 40th Joint Propulsion Conference, Ft. Lauderdale, FL, July 11-14, 2004.

[54] Kim, V., Kozlov, V., Semenov, A., and Shkarban, I., "Investigation of the boron nitride based ceramics sputtering yield under its bombardment by Xe and Kr ions," IEPC-01-073, 27th International Electric Propulsion Conference, Pasadena, CA, Oct. 15-19, 2001. 